\title{
PRÉ-CULTIVO DE ADUBOS VERDES E OCORRÊNCIA DE PLANTAS DANINHAS EM ÁREA DE PLANTIO DA CANA-PLANTA
}

\author{
Edmilson José Ambrosano ${ }^{1}$, Fabrício Rossi ${ }^{1}$, Dulcineia Elizabete Foltran ${ }^{2}$, Mônica Sartori \\ Camargo $^{1}$, Eliana Aparecida Schammass ${ }^{3}$, Gláucia Maria Bovi Ambrosano ${ }^{4}$, Fábio Luis Ferreira \\ $\operatorname{Dias}^{1}$

\footnotetext{
${ }^{1}$ APTA/IAC - Pólo Regional Centro-Sul, DDD/Apta, C.P. 28, CEP 13400-970 Piracicaba, SP Brasil, ambrosano@apta.sp.gov.br

${ }^{2}$ APTA/IAC - UPD Tietê - Pólo Regional Centro Sul, DDD/Apta, C.P. 28 13400-970 Piracicaba, SP Brasil.

${ }^{3}$ Instituto de Zootecnia, Bioestatística, R. Heitor Penteado, 56 13460-000- Nova Odessa, SP Brasil.

${ }^{4}$ UNICAMP/FOP Depto. de Odontologia Social, Bioestatistica, C.P. 52 13414-903- Piracicaba, SP Brasil.
}

\section{RESUMO}

Os adubos verdes proporcionam muitas vantagens ao agroecossistema, como proteção do solo e fornecimento de nitrogênio, mas há poucas informações sobre sua ação no controle de plantas daninhas em cana-planta. O estudo visou avaliar a produção de material vegetal fresco e seco de plantas utilizadas em pré-cultivo na cana-de-açúcar, sua infecção natural por fungos micorrizicos arbusculares (FMA) e sua relação com o controle de plantas daninhas e a produtividade agrícola e industrial da cana-de-açúcar. $\mathrm{O}$ experimento foi conduzido no período de outubro de 2006 a agosto de 2008 em um Argissolo Vermelho Amarelo (PVA), localizado em Tietê, SP. Utilizou-se delineamento experimental em blocos completos casualizados com cinco repetições, contendo 14 tratamentos. Os tratamentos foram semeados em outubro de 2006. A avaliação dos adubos verdes foi feita em março de 2007. Foi feito o plantio da cana em cada parcela, permanecendo no campo por 17 meses e sendo colhida em agosto de 2008. As avaliações de plantas daninhas foram feitas aos 0, 40, 60, 80 e 120 dias após o plantio da cana-de-açúcar. A crotalária-júncea, as mucunas preta, verde e cinza e o guandu IAC - Fava Larga apresentaram a maior produção de material vegetal seco e os maiores acúmulos de nutrientes, e promoveram a maior produtividade agrícola e industrial da cana-de-açúcar e a melhor ação no controle de plantas daninhas, sendo eficientes até 80 dias. A maior percentagem de infecção natural por micorrizas FMA foi observada nos tratamentos com soja, crotalária-juncea, girassol IAC Uruguai, feijão-mungo e guandu IAC- Fava Larga.

Palavras-chave: Saccharum spp., Arachis hypogaea, Crotalaria juncea, Mucuna aterrima

\section{PRODUCTIVITY OF SUGARCANE PLANT CROP AND OCCURRENCE OF WEEDS CULTIVED AFTER PREVIOUS LEGUMES CROP}

\section{ABSTRACT}

The green manures offer many advantages to the ecosystem by protecting soil and nitrogen supply however, information about weed control in sugarcane plant is scarse. This study evaluates and characterizes the yield of fresh and dried plant material of plants cultived after previous cover crop with sugarcane, its natural infection by arbuscular mycorrhizal fungi (AMF) and its relation to weed control and agricultural and industrial yield of sugarcane. The experiment was carried out from October 2006 to August 2008 in Hapludox soil, in Tietê, State of São Paulo, Brazil. We used randomized complete block design with 14 treatments and five replications. The 
treatments were sown on October 2006. The harvest of green manures was done on March 2007. Sugarcane planting was made of in each plot, on the field for 17 months and harvested on August 2008. The assessments were made of weeds at 0,40,60, 80 and 120 days after planting of cane sugar. Crotalaria juncea, the velvet, black, gray and green beans and pigeon pea IAC-Fava Larga showed the best production of dried plant material. They also promoted the higher accumulation of nutrients and increased agricultural and industrial yield of sugarcane and better effect on weed control up to 80 days. The largest percentage of mycorrhizal infection by AMF was observed in treatments with soybean, Crotalaria juncea, sunflower IAC-Uruguay, mung beans and pigeon beans IAC- Fava Larga.

Key words: Saccharum spp., Arachis hypogaea, Crotalaria juncea, Mucuna aterrima

\section{INTRODUÇÃO}

Com a expansão da área de cana-deaçúcar nos últimos anos, é fundamental a utilização de adubação adequada e outras técnicas para recuperar e melhorar o ambiente de produção, alcançar produtividade econômica, sustentabilidade agrícola e ambiental. Dentre os diversos recursos para melhorar as propriedades químicas, físicas e biológicas do solo, o uso de adubos verdes em áreas de reforma da cultura destaca-se em importância e viabilidade econômica (Ambrosano et al., 2010).

O ciclo comercial da cultura da cana, incluindo a cana planta e soqueiras, é de 5-8 anos, dependendo das características do solo e da cultivar. Como as colheitas diminuem com o tempo, essa cana deve ser replantada após esse ciclo. Entre os ciclos da cana, há um intervalo de tempo de cerca de 3-5 meses, geralmente na primavera e verão no Brasil central e sudeste, em que uma rotação de culturas pode ser cultivada. Caso contrário, o solo ficaria ocioso durante o período chuvoso (cerca de 950 milímetros em seis meses), sujeito ao aparecimento de ervas daninhas e erosão do solo (Cáceres \& Alcarde, 1995).

Os adubos verdes em áreas de reforma da cana-de-açúcar constituem, assim, alternativa importante para reciclagem de nutrientes (Mascarenhas et al., 1994), economia da adubação nitrogenada e geração de renda. A disponibilização de nutrientes contidos nos resíduos vegetais normalmente varia com a espécie de planta empregada para cobertura morta do solo (Ambrosano et al., 2010).

Outra associação microbiológica importante para as leguminosas usadas em pré-cultivo à cana-de-açúcar, além da associação com rizóbios para fixação simbiótica do nitrogênio, é a formada pelos fungos micorrízicos arbusculares (FMA). Estes fungos estão presentes em mais de $80 \%$ das espécies vegetais (Azcón et al., 1999). Utilizar uma cultura cujas raízes são colonizadas por fungos micorrízicos pode aumentar o potencial micorrízico do solo, que pode beneficiar as plantas que são cultivadas em sequência (Panja \& Chaudhuri, 2004; Espíndola et al., 1998).

Há várias formas de se controlar as plantas daninhas, entretanto as associações de métodos culturais mais comuns são: os mecânicos e os químicos (Procópio et al., 2003). Os métodos culturais são práticas que visam tornar a cultura da cana mais competitiva em relação às plantas daninhas e englobam a redução de espaçamentos de plantio, cultivos intercalares ou rotação de cultura com adubos verdes (Procópio et al., 2003).

O uso de coberturas mortas vegetais pode manter as populações reinfestantes em níveis toleráveis nas áreas cultivadas (Maclean et al., 2003). Os adubos verdes podem ser alternativa importante no controle 
de plantas daninhas devido à mudança da pressão de seleção, com alteração dos padrões de distúrbios (Severino \& Christoffoleti, 2001).

Assim, o presente trabalho teve como objetivo avaliar e caracterizar a produção de material vegetal fresco e seco de plantas utilizadas em rotação com cana-de-açúcar, sua infecção natural por fungos micorrizicos arbusculares (FMA) e sua relação com o controle de plantas daninhas até 120 dias após o plantio da cana-de-açúcar e seus efeitos na produtividade agrícola e industrial.

\section{MATERIAL E MÉTODOS}

$\mathrm{O}$ experimento foi desenvolvido em Tietê, SP $\left(23^{\circ} 07^{\prime} \mathrm{S}, 47^{\circ} 43^{\prime} \mathrm{W}\right.$ e $538 \mathrm{~m}$ de altitude), Brasil. Nada foi feito para correção da acidez do solo, bem como para elevação da quantidade de nutrientes disponíveis às plantas adubos verdes. O solo, classificado como Argissolo Vermelho Amarelo distrófico, foi caracterizado quimicamente após o corte do adubo verde, antes do plantio da cana-de-açúcar e revelaram: M.O. $=10 \mathrm{~g}$ $\mathrm{dm}^{-3} ; \mathrm{P}$ (resina) $=5 \mathrm{mg} \mathrm{dm}^{-3} ; \mathrm{K}, \mathrm{Ca}$ e $\mathrm{Mg}=$ 0,5; 26; $6 \mathrm{mmol}_{\mathrm{c}} \mathrm{dm}^{-3} ; \mathrm{pH}\left(\mathrm{CaCl}_{2}\right)=4,3 ; \mathrm{SB}$ $=32,5 \mathrm{mmol}_{\mathrm{c}} \mathrm{dm}^{-3} ; \mathrm{CTC}=65,5 \mathrm{mmol}_{\mathrm{c}} \mathrm{dm}^{-3}$ ; $\mathrm{V} \%=50 ; \mathrm{m} \%=16$ e S, B, Cu, Fe, $\mathrm{Mn}=8$; 0,$09 ; 0,6 ; 76 ; 16 \mathrm{mg} \mathrm{dm}^{-3}$. O experimento foi conduzido no período de outubro de 2006 a agosto de 2008 .

O delineamento foi blocos casualizados com 5 repetições e 14 tratamentos, sendo 12 espécies de plantas utilizadas em pré-cultivo a cana-de-açúcar: Amendoim IAC-Tatu (Arachis hypogaea L.), Amendoim IAC-Caiapó (Arachis hypogaea L.), Crotalária-juncea IAC-1 (Crotalaria juncea L.), Mucuna-preta (Mucuna aterrimum Piper and Tracy), Soja IAC-23 (Glycine max L. Merrill), Girassol IAC-Uruguai (Helianthus annuus L.), Feijão-mungo (Vigna radiata L. Wilczek), Mucuna-cinza (Mucuna cinerea L.), Mucuna-Verde (Mucuna pruriens (L.) DC. var. verde), Guandu IAC-Fava Larga (Cajanus cajan L.), Guandu IAC-Anão (Cajanus cajan L.), Girassol IAC-Iarama (Helianthus annuus L.), mais dois tratamentos testemunhas sem adubo verde, sendo um capinado (sem mato), e outro com o crescimento do mato. Quando se estudou a produção da biomassa e os nutrientes nos adubos verdes, foram considerados os primeiros 12 tratamentos.

A semeadura dos tratamentos foi realizada em novembro de 2006, no espaçamento de $0,5 \mathrm{~m}$ entre linhas. $\mathrm{O}$ tamanho de cada parcela foi de $7 \mathrm{~m}$ de largura e $8 \mathrm{~m}$ de comprimento. A colheita e avaliação dos adubos verdes foi feita em uma área útil de $1 \mathrm{~m}^{2}$ da área central de cada parcela, em março de 2007. A produtividade de grãos dos amendoins, soja, feijão-mungo e girassóis utilizados em rotação com canade-açúcar também foi avaliada. Desse material vegetal da parte aérea, uma amostra foi retirada para determinação de umidade em estufa de circulação forçada de ar, a uma temperatura de $60^{\circ} \mathrm{C}$. A amostra seca foi moída, em moinhos de faca tipo Willey, e utilizada para as determinações químicas de teores de elementos nutrientes (Bataglia et al. 1983).

Na colheita dos adubos verdes foram amostradas raízes das plantas para avaliar a porcentagem de colonização natural por fungos micorrízicos arbusculares (FMAs). O nível de colonização micorrízica foi estimado após coloração das raízes segundo Philips \& Hyman (1970), determinando-se a percentagem de colonização das raízes por observação em microscópio óptico com auxílio de uma placa reticulada, segundo metodologia proposta por Giovanetti \& Mosse (1980).

Após a colheita, a biomassa das plantas foi triturada e mantida sobre o solo, sendo a sulcagem para plantio da cana-deaçúcar feita diretamente sobre a cobertura vegetal. 
Foi feito o plantio da cana-de-açúcar (variedade IAC87-3396) em cada parcela, usando o espaçamento de 1,4 m entre linhas. A cana-de-açúcar não foi adubada no plantio, para verificar o potencial da adubação verde. Não foi utilizada irrigação e não foi feito controle de plantas daninhas, uma vez que era objetivo do estudo avaliar o efeito dos adubos verdes no controle das invasoras.

As avaliações de material de plantas daninhas foram feitas aos $0,40,60,80$ e 120 dias após o plantio da cana-de-açúcar. O material vegetal foi seco em estufa de circulação forçada de ar, a $60^{\circ} \mathrm{C}$ até peso constante.

Aos 17 meses a cana-de-açúcar foi colhida pela primeira vez (19/08/2008), sendo avaliado o peso em $\mathrm{kg}$ de uma amostra de colmos coletada em três seguimentos de 2 $\mathrm{m}$ lineares contínuos, no centro da parcela experimental, e calculada sua produtividade. Foram colhidas também amostras de dez colmos de cana seguidos na linha em cada tratamento (Tanimoto, 1964) para análise tecnológica de Brix\% e pol\% e cálculo de tonelada de pol por hectare (TPH) que nos da uma idéia da produção de açúcar.

Os dados relativos ao mato foram transformados em $1 /(\mathrm{x}+1)^{2}$, para atendimento das pressuposições do modelo matemático, e submetidos a análise univariada, em delineamento em blocos casualizados, esquema de parcela subdividida no tempo, considerando os 14 tratamentos como parcelas e as quatro épocas de amostragem do mato como subparcelas. O efeito das épocas de amostragem foi estudado por meio de analise de regressão polinomial.

Os dados de matéria fresca e seca dos adubos verdes, de cana-de-açúcar (colmos e pol) e a quantidade de material vegetal das plantas daninhas foram submetidos a análise de variância (ANOVA) e teste de ScottKnott para agrupamento médias dos tratamentos. O nível de significância adotado foi de 5\% utilizando-se o programa estatístico SISVAR (Ferreira, 2008).

Os dados referentes a nutrientes $(\mathrm{Kg}$ $\mathrm{ha}^{-1}$ ) foram transformados em $\log (\mathrm{X})$, a fim de atender as pressuposições da análise da variância. $\mathrm{O}$ delineamento experimental adotado foi em blocos casualizados, com 5 repetições e 12 tratamentos. Também foram utilizados o Teste de Scott-Knott, a 5\% de significância, e o programa estatístico SISVAR (Ferreira, 2008).

\section{RESULTADOS E DISCUSSÃO}

Houve efeito significativo para a produção de material verde e seco, para produção de grãos das plantas alimentícias e para infecção natural das raízes das plantas utilizadas em pré-cultivo por micorrizas. Observaram-se também efeito significativo para as variáveis teores e acúmulos de macronutrientes e na produtividade industrial e de açúcar, todas influenciadas pelos tratamentos aplicados.

A maior produção de material vegetal fresco dos adubos verdes foi obtida com a crotalária-juncea, as mucunas (preta, cinza e verde) e com os guandus (IAC-Anão e IAC-Fava Larga), concordando com Mascarenhas et al. (1994). As plantas alimentícias, por sua vez, tiveram rendimento inferior, destacando-se o feijãomungo e os amendoins IAC-Tatu e IACCaiapó (Tabela 1).

As produções de massa seca encontradas nesse experimento estão um pouco acima das obtidas por Cáceres \& Alcarde (1995), que encontraram produtividade de 7 e 3 toneladas por hectare para crotalária-juncea e mucuna-preta, respectivamente, e por Ambrosano et al. (2010), que obtiveram uma produtividade de 6 e 5 toneladas por hectare para crotaláriajuncea e mucuna-preta, respectivamente. Estes resultados indicam que as produtividades encontradas podem ser facilmente reproduzidas ou melhoradas pelos 
Tabela 1. Produção de material vegetal fresco e seco das plantas utilizadas em pré-cultivo a cana-de-açúcar, produção de grãos das plantas alimentícias e infecção natural por fungos micorrizicos arbusculares (FMA), Tietê, SP, 2006-2007.

\begin{tabular}{lcccc}
\hline Culturas utilizadas em & $\begin{array}{c}\text { Adubo verde } \\
\text { fresco }\end{array}$ & $\begin{array}{c}\text { Adubo verde } \\
\text { seco } \\
\text { Pré-cultivo a cana-de-açúcar }\end{array}$ & $\begin{array}{c}\text { Produção } \\
\text { de grãos }\end{array}$ & $\begin{array}{c}\text { Infecção } \\
\text { FMA }\end{array}$ \\
\hline Crotalária juncea IAC-1 & $21,9 \mathrm{a}$ & $10,0 \mathrm{a}$ & - & $67 \mathrm{a}$ \\
Guandu IAC-Fava Larga & $21,9 \mathrm{a}$ & $7,0 \mathrm{~b}$ & - & $69 \mathrm{a}$ \\
Guandu IAC-anão & $18,1 \mathrm{a}$ & $6,0 \mathrm{~b}$ & - & $53 \mathrm{~b}$ \\
Mucuna-preta & $26,9 \mathrm{a}$ & $5,3 \mathrm{c}$ & - & $48 \mathrm{~b}$ \\
Mucuna-cinza & $21,1 \mathrm{a}$ & $4,3 \mathrm{c}$ & - & $54 \mathrm{~b}$ \\
Mucuna-verde & $25,1 \mathrm{a}$ & $4,6 \mathrm{c}$ & - & $53 \mathrm{~b}$ \\
Amendoim IAC-Tatu & $11,4 \mathrm{~b}$ & $3,2 \mathrm{~d}$ & $1,55 \mathrm{~b}$ & $43 \mathrm{~b}$ \\
Amendoim IAC-Caiapó & $11,6 \mathrm{~b}$ & $3,7 \mathrm{~d}$ & $2,80 \mathrm{a}$ & $43 \mathrm{~b}$ \\
Testemunha (sem mato) & - & - & - & - \\
Soja IAC Foscarim-31 & $8,9 \mathrm{c}$ & $3,2 \mathrm{~d}$ & $2,70 \mathrm{a}$ & $73 \mathrm{a}$ \\
Girassol IAC-Uruguai & $7,1 \mathrm{c}$ & $3,6 \mathrm{~d}$ & $1,73 \mathrm{~b}$ & $69 \mathrm{a}$ \\
Feijão-mungo & $13,5 \mathrm{~b}$ & $4,9 \mathrm{c}$ & $1,71 \mathrm{~b}$ & $61 \mathrm{a}$ \\
Girassol IAC-Iarama & $3,3 \mathrm{~d}$ & $2,4 \mathrm{e}$ & $0,90 \mathrm{c}$ & $49 \mathrm{~b}$ \\
Testemunha (com mato) & - & - & - & - \\
\hline CV*(\%) & 17,36 & 18,79 & 24,97 & 21,83 \\
\hline
\end{tabular}

Em cada coluna, médias seguidas de mesma letra pertencem ao mesmo agrupamento pelo teste de Scott-Knott a $5 \%$ de probabilidade.

agricultores, desde que respeitado o limite máximo de dezembro para semeadura das leguminosas e que ocorram condições favoráveis de solo e clima.

Observa-se que houve diferença de produtividade entre os cultivares de amendoim (Tabela 1). Quaggio \& Godoy (1996) consideraram, para o Estado de São Paulo, três classes de produtividade para o amendoim em sistema convencional: baixa menor que $1.500 \mathrm{~kg} \mathrm{ha}^{-1}$; média - entre 1.500 e $3.000 \mathrm{~kg} \mathrm{ha}^{-1}$; e alta - maior que $3.000 \mathrm{~kg} \mathrm{ha}^{-1}$. Observa-se (Tabela 1) que a produtividade foi média para ambos os cultivares, contudo, o fato de se produzir grãos nesse sistema permite gerar uma renda extra ao produtor, que pode ser importante dentro do sistema. Ambrosano et al. (2010) encontraram produtividades baixas para os mesmos cultivares de amendoim e um custo de produção muito alto para as condições de Piracicaba. Isso pode ser devido a falta de prática de rotação nessa região, sendo que a região produtora de Ribeirão Preto pratica rotação com amendoim com excelentes resultados.

A quantidade de material vegetal seco que permanecerá no solo, por sua vez, é um item indispensável para avaliação dos efeitos dos adubos verdes no solo e na emergência das plantas daninhas. A crotalária-juncea continuou com o melhor rendimento, seguida dos guandus IAC-anão e IAC-Fava Larga, os quais não diferiram entre si (Tabela 1).

Quanto às plantas alimentícias, o feijão-mungo apresentou melhor resultado, não ocorrendo diferença entre os amendoins IAC-Tatu e IAC-Caiapó, a soja IAC-23, o girassol IAC-Uruguai (Tabela 1). Dentre eles, o girassol IAC-Iarama não apresentou bom desempenho. $\mathrm{O}$ feijão-mungo representa alternativa importante de geração de renda ao produtor pela possibilidade de agregação de valor ao produto final, que seria a produção de brotos comestíveis 
(moyashi), segundo Ambrosano et al. (2010).

Observa-se (Tabela 1) que essas plantas utilizadas em rotação apresentaram, com exceção dos amendoins Tatu e IACCaiapó, mucuna-preta, e girassol IACYarama, mais da metade de seu sistema radicular infectado naturalmente por fungos micorrízicos arbusculares. Esse fato vai refletir no bom desempenho dessas plantas em crescer, desenvolvendo seu sistema radicular para melhor explorar o solo a busca de águas e micronutrientes. Trabalhos desenvolvidos por Panja \& Chaudhuri (2004), têm mostrado a importância do préplantio de leguminosas para o enriquecimento de micorrizas em solo de viveiro de laranja. Segundo Espíndola et al. (1998), o pré cultivo de leguminosas adubo verde aumentou o número de propágulos infectivos de fungos micorrízicos com consequente aumento na produtividade de batata-doce. Ambrosano et al. (2010), observaram que a infecção natural por micorrizas se correlacionou positivamente com a altura da cana-de-açúcar quando do pré cultivo de leguminosas adubo verde, em áreas de renovação do canavial.

Notam-se diferenças estatísticas entre os teores de macronutrientes presentes na parte aérea (Tabela 2) e os acúmulos de macronutrientes na matéria seca produzida pelas plantas utilizadas em rotação com a cana-de-açúcar (Tabela 3). O amendoim IAC-Caiapó, crotalária-juncea, as mucunas preta, cinza e verde, e o guandu IAC-Fava larga foram as plantas que apresentaram maiores teores de nitrogênio e os girassóis os menores valores, confirmando a elevada fixação biológica de nitrogênio que determina esse resultado (Tabela 2 ).

Os maiores acúmulos ficaram por conta da crotalária-juncea, seguida da mucuna-preta e guandu IAC-Fava larga, chegando a $222 \mathrm{~kg}$ de nitrogênio acumulados e $123 \mathrm{~kg}$ de potássio acumulados, indicando ser essa planta um agente importante de incorporação e reciclagem de nutrientes (Tabela 3). Resultados semelhantes foram alcançados por Cáceres \& Alcarde (1995), que encontraram acúmulos de 235 e 102 kg por hectare de nitrogênio e potássio, respectivamente, para crotalária-juncea, indicando o grande potencial de incorporação de nitrogênio e reciclagem de potássio.

Houve efeito de alguns adubos verdes sobre a produção de colmos da canade-açúcar em relação aos tratamentos testemunhas capinado e com mato (Tabela 4). Pode-se observar que o efeito do précultivo de adubos verdes nas áreas de reforma do canavial promoveu benefícios em termos do aumento da produtividade da cana-planta, sendo destaque o pré-cultivo com a crotalária-juncea, as mucunas preta, cinza e verde, e o guandu IAC-Fava Larga.

Vale notar que crotalária-juncea apresentou maior produção de matéria seca, e isso pode estar influenciando positivamente no crescimento do canavial. Mascarenhas et al. (1994) evidenciaram efeito positivo da adubação verde com crotalária-juncea em cana-de-açúcar, com produtividade superior à aplicação ao solo de $40 \mathrm{~kg} \mathrm{ha}^{-1}$ de N-mineral. Ambrosano et al. (2005), conduziram um experimento com cana-de-açúcar após rotação com crotaláriajuncea com adição conjunta e separada de adubação mineral de nitrogênio (70 kg ha-1 de $\mathrm{N})$ e observaram que a cana-planta acumulou até o final do primeiro corte quantidades de $\mathrm{N}$ semelhantes, provenientes tanto do fertilizante mineral (sulfato de amônio) quanto do adubo verde (crotaláriajuncea).

Isso implica em dizer que crotaláriajuncea supriu completamente as demandas da cana-planta em termos de nitrogênio, contudo a utilização das duas fontes conjuntamente implicou em um melhor rendimento da cana-de-açúcar em produção agrícola e industrial. 
Tabela 2. Média dos teores de macronutrientes contidos nas leguminosas utilizadas em rotação com cana-de-açúcar, Tietê, SP, 2007.

\begin{tabular}{|c|c|c|c|c|c|}
\hline $\begin{array}{l}\text { Culturas utilizadas em pré- cultivo à } \\
\text { cana-de-açúcar }\end{array}$ & $\mathrm{N}$ & $\mathrm{P}$ & $\begin{array}{c}\mathrm{K} \\
\mathrm{g} \mathrm{kg}^{-1}\end{array}$ & $\mathrm{Ca}$ & $\mathrm{Mg}$ \\
\hline Mucuna-preta & $22,25 \mathrm{a}$ & $1,73 \mathrm{~b}$ & $14,15 \mathrm{~b}$ & $11,12 \mathrm{~b}$ & $2,94 \mathrm{c}$ \\
\hline Mucuna-cinza & 20,79 a & $1,52 \mathrm{~b}$ & $10,85 \mathrm{~b}$ & $12,96 \mathrm{c}$ & $3,76 \mathrm{c}$ \\
\hline Crotalária-juncea IAC-1 & $20,43 \mathrm{a}$ & $1,88 \mathrm{~b}$ & $14,03 \mathrm{~b}$ & $7,90 \mathrm{~d}$ & $4,53 \mathrm{~b}$ \\
\hline Mucuna-verde & $19,49 \mathrm{a}$ & $1,46 \mathrm{~b}$ & $14,34 \mathrm{~b}$ & $10,12 \mathrm{~b}$ & $3,22 \mathrm{c}$ \\
\hline Amendoim IAC-Caiapó & $19,18 \mathrm{a}$ & $1,58 \mathrm{~b}$ & $20,34 \mathrm{a}$ & $14,17 \mathrm{c}$ & $5,72 \mathrm{~b}$ \\
\hline Guandu IAC-Fava Larga & $18,91 \mathrm{a}$ & $1,67 \mathrm{~b}$ & $13,31 \mathrm{~b}$ & $7,33 \mathrm{~d}$ & $2,42 \mathrm{~d}$ \\
\hline Amendoim IAC-Tatu & $16,58 \mathrm{~b}$ & $1,39 \mathrm{~b}$ & $17,15 \mathrm{a}$ & $18,44 \mathrm{a}$ & $7,59 \mathrm{a}$ \\
\hline Guandu IAC-anão & $16,49 \mathrm{~b}$ & $1,58 \mathrm{~b}$ & $11,33 \mathrm{~b}$ & $5,46 \mathrm{~d}$ & $1,84 \mathrm{~d}$ \\
\hline Soja IAC-23 & $16,38 \mathrm{~b}$ & $2,69 \mathrm{a}$ & $15,91 \mathrm{~b}$ & $11,22 \mathrm{~b}$ & $5,01 \mathrm{~b}$ \\
\hline Feijão-mungo & $13,29 \mathrm{~b}$ & $1,58 \mathrm{~b}$ & $15,00 \mathrm{~b}$ & $9,22 \mathrm{~b}$ & $5,91 \mathrm{~b}$ \\
\hline Girassol IAC-Iarama & $6,47 \mathrm{c}$ & $1,73 \mathrm{~b}$ & $21,66 \mathrm{a}$ & $11,59 \mathrm{~b}$ & $5,22 \mathrm{~b}$ \\
\hline Girassol IAC-Uruguai & $4,14 \mathrm{c}$ & $1,33 \mathrm{~b}$ & $19,84 \mathrm{a}$ & $9,67 \mathrm{~b}$ & $4,35 \mathrm{~b}$ \\
\hline Testemunha (sem mato) & -- & -- & -- & -- & -- \\
\hline Testemunha (com mato) & -- & -- & -- & -- & -- \\
\hline Média & 16,20 & 1,68 & 15,66 & 10,77 & 4,38 \\
\hline $\mathrm{CV}(\%)$ & 24,23 & 24,28 & 22,04 & 16,96 & 20,98 \\
\hline
\end{tabular}

Em cada coluna, médias seguidas de mesma letra pertencem ao mesmo agrupamento pelo teste de Scott-Knott a $5 \%$ de probabilidade.

Tabela 3. Média dos acúmulos de macronutrientes contidos nas leguminosas utilizadas em rotação com cana-de-açúcar, Tietê, SP, 2007.

\begin{tabular}{|c|c|c|c|c|c|}
\hline $\begin{array}{l}\text { Culturas utilizadas em pré- cultivo } \\
\text { à cana-de-açúcar }\end{array}$ & $\mathrm{N}$ & $\mathrm{P}$ & $\begin{array}{c}\mathrm{K} \\
-\mathrm{kg} \mathrm{ha}^{-}\end{array}$ & $\mathrm{Ca}$ & $\mathrm{Mg}$ \\
\hline Crotalária-juncea IAC-1 & $221,9 \mathrm{a}$ & $16,8 \mathrm{a}$ & $123,4 \mathrm{a}$ & $87,7 \mathrm{a}$ & $49,2 \mathrm{a}$ \\
\hline Guandu IAC-Fava Larga & $132,3 \mathrm{~b}$ & $11,7 \mathrm{~b}$ & $93,7 \mathrm{a}$ & $51,1 \mathrm{~b}$ & $17,0 \mathrm{c}$ \\
\hline Mucuna-preta & $118,4 \mathrm{~b}$ & $9,2 \mathrm{c}$ & $76,1 \mathrm{~b}$ & $59,7 \mathrm{~b}$ & $15,5 \mathrm{c}$ \\
\hline Guandu IAC-anão & $99,5 \mathrm{c}$ & $9,4 \mathrm{c}$ & $67,7 \mathrm{~b}$ & $32,4 \mathrm{c}$ & $10,9 \mathrm{c}$ \\
\hline Mucuna-cinza & $89,9 \mathrm{c}$ & $6,6 \mathrm{~d}$ & $45,8 \mathrm{~b}$ & $56,7 \mathrm{~b}$ & $16,3 \mathrm{c}$ \\
\hline Mucuna-verde & $89,4 \mathrm{c}$ & $6,5 \mathrm{~d}$ & $63,7 \mathrm{~b}$ & $47,1 \mathrm{c}$ & $15,1 \mathrm{c}$ \\
\hline Amendoim IAC-Caiapó & $70,4 \mathrm{c}$ & $5,8 \mathrm{~d}$ & $74,6 \mathrm{~b}$ & $52,0 \mathrm{~b}$ & $21,3 \mathrm{~b}$ \\
\hline Feijão-mungo & $64,8 \mathrm{~d}$ & $7,8 \mathrm{c}$ & $73,2 \mathrm{~b}$ & $44,6 \mathrm{c}$ & $28,2 \mathrm{~b}$ \\
\hline Soja IAC-23 & $55,6 \mathrm{~d}$ & $8,3 \mathrm{c}$ & $51,9 \mathrm{~b}$ & $36,0 \mathrm{c}$ & $15,8 \mathrm{c}$ \\
\hline Amendoim IAC-Tatu & $53,5 \mathrm{~d}$ & $4,4 \mathrm{e}$ & $54,2 \mathrm{~b}$ & $59,0 \mathrm{~b}$ & $24,4 \mathrm{~b}$ \\
\hline Girassol IAC-Uruguai & $14,6 \mathrm{e}$ & $4,6 \mathrm{e}$ & $70,6 \mathrm{~b}$ & $34,5 \mathrm{c}$ & $15,6 \mathrm{c}$ \\
\hline Girassol IAC-Iarama & $14,2 \mathrm{e}$ & $3,7 \mathrm{e}$ & $54,9 \mathrm{~b}$ & $28,3 \mathrm{c}$ & $12,4 \mathrm{c}$ \\
\hline Testemunha (sem mato) & -- & -- & -- & -- & -- \\
\hline Testemunha (com mato) & -- & -- & -- & -- & -- \\
\hline Média & 85,4 & 7,9 & 70,8 & 49,1 & 20,1 \\
\hline $\mathrm{CV}(\%)$ & 34,79 & 18,82 & 34,59 & 26,69 & 25,94 \\
\hline
\end{tabular}

Em cada coluna, médias seguidas de mesma letra pertencem ao mesmo agrupamento pelo teste de Scott-Knott a $5 \%$ de probabilidade. 
Tabela 4. Toneladas de colmos por hectare (TCH) e toneladas de pol por hectare (TPH), Tietê $(19 / 08 / 2008)$.

\begin{tabular}{lcc}
\hline $\begin{array}{l}\text { Culturas utilizadas em pré-cultivo à } \\
\text { cana-de-açúcar }\end{array}$ & Cana-de-açúcar TCH & Cana-de-açúcar TPH \\
\hline Mucuna-preta & $----36 \mathrm{a}$ & $9,97 \mathrm{a}$ \\
Crotalária- juncea IAC-1 & $64,32 \mathrm{a}$ & $10,07 \mathrm{a}$ \\
Mucuna-verde & $58,29 \mathrm{a}$ & $8,71 \mathrm{a}$ \\
Guandu IAC-Fava Larga & $54,09 \mathrm{a}$ & $8,30 \mathrm{a}$ \\
Mucuna-cinza & $48,31 \mathrm{a}$ & $7,20 \mathrm{a}$ \\
Guandu IAC-anão & $42,68 \mathrm{~b}$ & $6,30 \mathrm{~b}$ \\
Amendoim IAC-Tatu & $41,95 \mathrm{~b}$ & $6,16 \mathrm{~b}$ \\
Soja IAC-23 & $39,15 \mathrm{~b}$ & $5,95 \mathrm{~b}$ \\
Girassol IAC-Uruguai & $38,35 \mathrm{~b}$ & $5,77 \mathrm{~b}$ \\
Feijão-mungo & $35,24 \mathrm{~b}$ & $5,13 \mathrm{~b}$ \\
Testemunha (sem mato) & $32,68 \mathrm{~b}$ & $4,69 \mathrm{~b}$ \\
Amendoim IAC-Caiapó & $32,30 \mathrm{~b}$ & $4,77 \mathrm{~b}$ \\
Girassol IAC-Iarama & $28,09 \mathrm{~b}$ & $4,19 \mathrm{~b}$ \\
Testemunha (com mato) & $26,71 \mathrm{~b}$ & $3,53 \mathrm{~b}$ \\
\hline Média & 43,46 & 6,48 \\
\hline CV*(\%) & 16,18 & 17,49
\end{tabular}

Em cada coluna, médias seguidas de mesma letra pertencem ao mesmo agrupamento pelo teste de Scott-Knott a $5 \%$ de probabilidade.

Observa-se também (Tabela 4) que a produtividade de açúcar do melhor tratamento foi o dobro da testemunha, resultado que supera em muito os obtidos por Mascarenhas et al. (1994) e Cáceres \& Alcarde (1995), que encontraram incremento de 2,98 t de açúcar por hectare, e os efeitos da adubação verde foram sentidos mais na cana-planta, como é o caso desse experimento. Ambrosano et al., (2010), trabalharam com sete espécies de plantas em rotação com cana-de-açúcar em áreas de reforma e encontraram aumentos na produção de açúcar em torno de 50\% nos tratamentos com girassol IAC-Uruguai e $35 \%$ para crotalária-júncea. No presente estudo, os resultados de produtividade agrícola e industrial foram muito baixos em comparação com os obtidos em outros experimentos, e isso pode ser explicado em parte devido a condições de solo e clima, mas principalmente pela não aplicação de fertilizantes no plantio da cana-de-açúcar.
As plantas daninhas que predominaram nas amostragens foram Cypro- Cyperus rotundus L.; PanmaPanicum maximum Jacq.; Brapl- Brachiaria plantagina (Link) Hitchc.; BradcBrachiaria decumbens Stapf.; e CyndaCynodon dactylon (1.) Pers.

Houve efeito significativo da interação das plantas utilizadas em précultivo à cana-de-açúcar com a época de avaliação até os 80 dias, a partir desse instante não se observou efeito dos adubos verdes no efetivo controle do mato.

Todas as rotações empregadas no experimento apresentaram comportamento quadrático (Tabela 5) em relação a produção de material vegetal seco de mato em função das épocas de avaliação, a exceção do tratamento testemunha (sem mato) cujo comportamento foi linear (Figura 1), indicando que, apesar do efetivo controle até os 80 dias de avaliação, as plantas daninhas continuaram seu ritmo de crescimento. 
Tabela 5. Comparação entre produção de matéria seca de plantas daninhas e tipo de regressão polinomial para as diversas épocas de avaliação, Tietê, SP, 2006-2007.

\begin{tabular}{|c|c|c|c|c|c|c|c|}
\hline \multirow{3}{*}{$\begin{array}{l}\text { Culturas utilizadas em pré- } \\
\text { cultivo à cana-de-açúcar }\end{array}$} & \multicolumn{4}{|c|}{$\begin{array}{c}\text { Avaliação do mato } \\
\text { (Dias após plantio da cana) }\end{array}$} & \multicolumn{3}{|c|}{ Regressões } \\
\hline & 0 & 40 & 80 & 120 & RL & RQ & $\mathrm{R}^{2}$ \\
\hline & \multicolumn{7}{|c|}{------------------ $\mathrm{Kg} \mathrm{m}^{-2}$} \\
\hline Amendoim IAC-Tatu & $0,074 d$ & $0,319 \mathrm{a}$ & $0,171 \mathrm{a}$ & $0,957 \mathrm{a}$ & $* *$ & $* *$ & $0,80 * *$ \\
\hline Amendoim IAC-Caiapó & $0,180 \mathrm{c}$ & $0,274 \mathrm{a}$ & $0,165 \mathrm{a}$ & $1,015 \mathrm{a}$ & $* *$ & $* *$ & $0,83 * *$ \\
\hline Testemunha (sem mato) & $0,008 \mathrm{~d}$ & $0,333 \mathrm{a}$ & 0,205 a & $0,833 \mathrm{a}$ & $* *$ & NS & $0,79 * *$ \\
\hline Crotalária-juncea IAC-1 & $0,152 \mathrm{c}$ & $0,024 \mathrm{a}$ & $0,098 \mathrm{~b}$ & $0,918 \mathrm{a}$ & $* *$ & $* *$ & $0,99 * *$ \\
\hline Mucuna-preta & $0,000 \mathrm{e}$ & $0,055 \mathrm{c}$ & $0,117 \mathrm{~b}$ & $1,418 \mathrm{a}$ & $* *$ & $* *$ & $0,96 * *$ \\
\hline Soja IAC-23 & $0,028 \mathrm{~d}$ & $0,134 \mathrm{~b}$ & $0,196 \mathrm{a}$ & $1,361 \mathrm{a}$ & $* *$ & $* *$ & $0,95 * *$ \\
\hline Girassol IAC-Uruguai & $0,152 \mathrm{c}$ & $0,274 \mathrm{a}$ & $0,191 \mathrm{a}$ & $1,364 \mathrm{a}$ & $* *$ & $* *$ & $0,88 * *$ \\
\hline Feijão-mungo & $0,042 d$ & $0,151 \mathrm{~b}$ & $0,181 \mathrm{a}$ & $1,119 \mathrm{a}$ & $* *$ & $* *$ & $0,94 * *$ \\
\hline Mucuna-cinza & $0,344 b$ & $0,035 \mathrm{~b}$ & $0,047 \mathrm{~b}$ & $1,520 \mathrm{a}$ & $* *$ & $* *$ & $0,96^{* *}$ \\
\hline Mucuna-verde & $0,000 \mathrm{e}$ & $0,019 \mathrm{c}$ & $0,033 \mathrm{~b}$ & $1,615 \mathrm{a}$ & $* *$ & $* *$ & $0,94 * *$ \\
\hline Guandu IAC-Fava Larga & $0,036 \mathrm{~d}$ & $0,031 \mathrm{c}$ & $0,067 \mathrm{~b}$ & $0,796 a$ & $* *$ & $* *$ & $0,96^{* *}$ \\
\hline Guandu IAC-anão & $0,035 d$ & $0,135 \mathrm{~b}$ & $0,167 \mathrm{a}$ & $1,465 \mathrm{a}$ & $* *$ & $* *$ & $0,94 * *$ \\
\hline Girassol IAC-Iarama & $0,342 b$ & $0,288 \mathrm{a}$ & $0,253 \mathrm{a}$ & $1,116 \mathrm{a}$ & $* *$ & $* *$ & $0,91 * *$ \\
\hline Testemunha (com mato) & $1,616 \mathrm{a}$ & $0,579 \mathrm{a}$ & $0,299 \mathrm{a}$ & $1,611 \mathrm{a}$ & NS & $* *$ & $0,94 * *$ \\
\hline $\mathrm{CV}(\%)$ tratamentos & 29,41 & & & & & & \\
\hline CV $(\%)$ época & 18,25 & & & & & & \\
\hline
\end{tabular}

Em cada coluna, médias seguidas de mesma letra pertencem ao mesmo agrupamento pelo teste de Scott-Knott a $5 \%$ de probabilidade.

Dados transformados em $1 /(x+1)^{2}$ para fins de análise de variância.

Esse comportamento é muito importante para a cultura da cana, uma vez que o período crítico de competição vai da emergência dos brotos de cana até os 30 dias e a maioria dos cultivares de cana-de-açúcar necessitam de um controle das plantas daninhas até os 90 dias (Arévalo et al. 1974).

Observa-se (Figura 1) que as mucunas, preta e cinza e o guandu IAC-Fava Larga foram os que apresentaram o melhor controle das plantas daninhas, permanecendo a cana-planta no limpo até os 22 dias para mucuna-preta e 33 dias para o guandu IACFava Larga e a mucuna-cinza, dando ao canavial uma vantagem competitiva, refletindo em maior produtividade para esses tratamentos, os quais se situaram no grupo mais produtivo (Tabela 4).

No grupo menos produtivo ficaram as duas testemunhas, que não receberam o efeito da cobertura vegetal e nem do nitrogênio, e outros tratamentos que não produziram tanta massa vegetal ou que permitiram o desenvolvimento das plantas daninhas, a exceção da crotalária-juncea que só conseguiu deixar a cultura limpa até os 40 dias e a mucuna-verde até os 42 dias, ficando um pouco acima do recomendado que seria em torno dos 30 dias (Arévalo et al., 1974).

Houve menor quantidade de mato aos 40 dias com o guandu IAC - Fava Larga e mucunas, preta e verde, seguida da soja IAC-23 (Tabela 5 e Figura 1). Esses resultados podem estar relacionados à degradabilidade do material disposto sobre o solo, embora não tenham sido aqueles com maior produção de matéria seca obtida na colheita, pois essa decomposição pode gerar ácidos orgânicos, com efeito alelopático às plantas daninhas ( Putnam et al., 1983). 


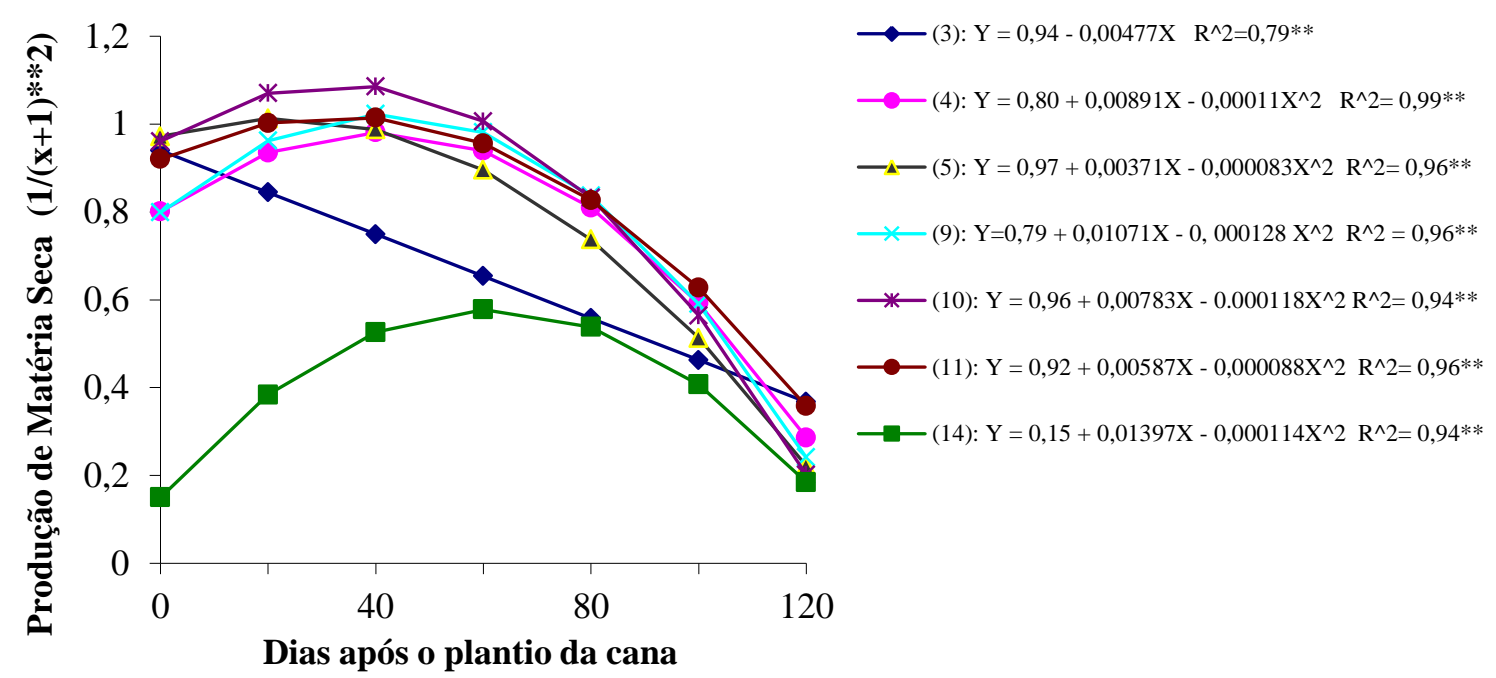

Figura 1. Curvas representando o comportamento do mato nos tratamentos (3)Testemunha sem mato no pré-cultivo, (4) Crotalária-juncea, (5) Mucuna-preta, (9) Mucuna-verde, (10) Mucuna-cinza, (11) Guandu IAC-Fava Larga e (14) Testemunha com mato no précultivo. Essas equações acusaram os pontos de máximo (nessa transformação inversa de $1 /(\mathrm{x}+1)^{2}$, que correspondem aos pontos de mínimo nos dados originais) de (4) Crotalária-juncea, 40 dias; (5) Mucuna-preta, 22 dias; (9) Mucuna-verde, 42 dias; (10) Mucuna-cinza, 33 dias; (11) Guandu IAC-Fava Larga 33dias e (14) Testemunha com mato 61 dias.

Essa ação alelopática impede ou diminui a germinação e o desenvolvimento das plantas daninhas (Favero et al., 2001). Os compostos químicos responsáveis pela alelopatia são denominados aleloquímicos e cada espécie pode produzir um conjunto diferente de aleloquímicos, com ação diferenciada sobre os componentes da comunidade em que está inserida (Putnam et al., 1983), dependendo, principalmente, da quantidade do material vegetal depositado na superfície, do tipo de solo, da população microbiana e das condições climáticas (Pitelli, 1985).

Aos 80 dias, as mucunas, verde e preta continuaram com melhor controle do mato, sendo similares à mucuna-cinza e a crotalária-juncea, enquanto os outros tratamentos não diferiram entre si. Isso pode ser explicado pela possível liberação de substâncias (aleloquímicos) que inibam o desenvolvimento do mato após sua degradação. Resultados semelhantes foram encontrados por Favero et al. (2001), estudando feijão-bravo-do-ceará (Canavalia brasiliensis Mart ex Benth), mucuna-preta, lab-lab (Dolichos lablab L.) e guandu no controle de plantas invasoras; a mucunapreta destacou se das demais quanto à capacidade de recobrir o solo e controlar as plantas invasoras.

Monquero et al. (2009) também observaram que a cobertura do solo com mucuna-preta (Mucuna aterrimum Piper e Tracy), tanto deixada na superfície como incorporada ao solo, foi a mais eficiente na redução da emergência de corda-de-viola (Ipomoea grandifolia). Para capimbraquiária (Brachiaria decumbens) e capimcolonião (Panicum maximum) destacaram-se como melhores supressoras o milheto (Pennisetum glaucum) e a crotalária-juncea 
(Crotalaria juncea L.). Isso demonstra a importância de se estudar o efeito de diferentes coberturas sobre distintas espécies daninhas, ou seja, algumas coberturas podem ser mais eficazes na supressão de espécies daninhas específicas, sendo uma ferramenta importante no manejo integrado de plantas daninhas.

Fontanétti et al. (2004) trabalharam com a semeadura dos adubos verdes e, em seguida, o plantio de alface e repolho. Os autores utilizaram as leguminosas mucunapreta (Mucuna aterrimum, Piper e Tracy), feijão-de-porco (Canavalia ensiformes DC), crotalária-juncea (Crotalaria juncea L.) e uma testemunha (vegetação espontânea) e as culturas de alface-americana 'Raider' e repolho 'Kenzan'. Eles observaram que as espécies utilizadas mostraram-se eficientes no controle de tiririca (Cyperus rotundus L.), especialmente a mucuna-preta e o feijão-deporco, possivelmente por efeito alelopático, e o cultivo de repolho proporcionou maior redução da infestação de tiririca do que o da alface-americana.

Dessa maneira, a fitomassa produzida pela adubação verde tem influência direta na supressão de plantas daninhas nos agroecossistemas, pois existe correlação linear entre a quantidade desta fitomassa e a efetiva redução da infestação por plantas daninhas, e diferentes espécies de adubos verdes modificam a composição da população das plantas daninhas infestantes na área (Almeida, 1991). Também a cobertura morta altera as características físicas, químicas e biológicas do solo, modificando a constituição qualitativa e quantitativa do complexo florístico que se desenvolve nesse local, interferindo no processo de quebra de dormência das sementes e, devido à sua ação alelopática, na germinação e no desenvolvimento das plântulas (Almeida, 1991).

Santos et al. (2011) encontraram resultados semelhantes quando avaliaram o efeito de coberturas mortas com resíduos de diferentes espécies de plantas no rendimento da cenoura em cultivo orgânico e nos níveis de reinfestação pela vegetação espontânea. Os tratamentos consistiram de coberturas com a biomassa aérea, seca e triturada, de capim Cameroon (Pennisetum purpureum), gliricídia (Gliricidia sepium) e guandu (Cajanus cajan), além da testemunha (sem qualquer cobertura). Por ocasião da colheita da cenoura, os autores determinaram a produtividade e as médias em peso, comprimento e diâmetro máximo das raízes tuberosas. A cenoura cultivada nas parcelas tratadas com resíduos de leguminosas apresentou aumentos significativos de todas as variáveis fitotécnicas, com exceção do comprimento médio da raiz. Nas parcelas cobertas com resíduos da gramínea, os resultados foram estatisticamente iguais aos da testemunha. A reinfestação por plantas espontâneas por unidade de área cultivada alcançou níveis da ordem de $300 \%$ superiores em parcelas sem cobertura do solo, na comparação com aquelas que receberam as palhadas.

Mateus et al. (2004) avaliaram o efeito da quantidade de palhada do sorgo de guiné gigante sobre a população de plantas daninhas em área de plantio direto. Os tratamentos constaram de $0,6.100,7.100$, $19.500,26.700,28.100$ e $30.200 \mathrm{~kg} \mathrm{ha}^{-1} \mathrm{de}$ palhada do sorgo de guiné sobre os quais foi realizada a semeadura de soja cultivar Monsoy-6101 na densidade de 25 sementes por metro e no espaçamento de $0,45 \mathrm{~m}$ entre linhas. Trinta dias após a semeadura, houve redução significativa do número de plantas daninhas estabelecidas com o incremento da palhada. Os autores encontraram que a partir de $15 \mathrm{t} \mathrm{ha}^{-1}$, o controle de plantas daninhas foi superior a noventa por cento.

Finalmente, aos 120 dias não houve diferença entre os tratamentos, o que seria importante para a cultura da cana, uma vez que nesse período ela já saiu do período crítico de competição com as plantas daninhas (Tabela 5). 


\section{CONCLUSÕES}

A crotalária-juncea, as mucunas (preta, cinza e verde) e os guandus (anão IAC e IAC fava larga) apresentam maior produção de material vegetal fresco. Dentre as alimentícias, destacam-se o feijão-mungo e os amendoins IAC-Tatu e IAC-Caiapó.

Os adubos verdes apresentam maior controle efetivo do mato que as plantas alimentícias.

A crotalária-juncea, as mucunas verde, preta e cinza e o guandu IAC - Fava Larga são eficientes até os 80 dias no controle efetivo de plantas daninhas, assegurando bom desenvolvimento da canade-açúcar. A maior produção de fitomassa desses adubos verdes resultou em maior produtividade industrial e de açúcar.

\section{AGRADECIMENTOS}

Ao $\quad \mathrm{CNPq}$ pela bolsa de produtividade em pesquisa do primeiro autor.

\section{REFERÊNCIAS BIBLIOGRÁFICAS}

ALMEIDA, F. S. 1991. Controle de plantas daninhas em plantio direto. Londrina, 33p. (Circular IAPAR, 67)

AMBROSANO, E. J.; AZCÓN R.; CANTARELLA, H.; AMBROSANO, G. M. B.; SCHAMMASS, E. A.; TRIVELIN, P. C. O.;MURAOKA, T; ROSSI, F.; GUIRADO, N.; UNGARO, M. R. G.; TERAMOTO J. R. S. 2010. Crop rotation biomass and arbuscular mycorrhizal fungi effects on sugarcane yield. Scientia Agricola, v.67, n.6, p.692-701.

AMBROSANO, E. J.; TRIVELIN, P. C. O.; CANTARELLA, H.; AMBROSANO, G. M. B.; SCHAMMASS, E. A.; GUIRADO, N.; ROSSI, F.; MENDES, P. C. D. MURAOKA, T. 2005. Utilization of nitrogen from green manure and mineral fertilizer by sugarcane. Scientia Agricola, v.62, n.6, p.534-542.

ARÉVALO, R.A.; CERRIZUELA, E.A.; SOLDATI, A. 1974. Competencia de malezas específicas en caña planta. I. Cyperus rotundus. I. Reunião argentina de Malezas y su Control, 1972, Tucumán. Malezas y su Control (ASAM) v.3, n.1, p. 35-43.

AZCÓN, R. 1999. Importancia de los microrganismos rizosféricos en el crecimiento, nutrición vegetal y sostenibilidad agrícola. IN: AMBROSANO, E. J. . Agricultura Ecológica. 1. ed. Guaíba, RS: Livraria e Editora Agropecuária LTDA, v. 1. 398 p.

BATAGLIA, O. C.; FURLANI, A. M. C.; TEIXEIRA; J. P. F.; FURLANI, P. R.; GALlO, J. R. 1983. Métodos de análises químicas de plantas. Campinas: Instituto Agronômico, 48p. (Boletim Técnico, 78)

CÁCERES, N. T.; ALCARDE, J. C. 1995. Adubação verde com leguminosas em rotação com cana-de-açúcar (Saccharum spp). SociedaTécnica dos Açúcareiros e Álcooleiros do Brasil, STAB,v.13, n.5, p.16-20.

ESPÍNDOLA, J. A. A.; ALMEIDA, D. L.; GUERRA, J. G. M.; SILVA, E. M. R.; SOUZA, F. A. 1998. Influência da adubação verde na colonização micorrízica e na produção da batatadoce. Pesquisa Agropecuária Brasileira, Brasília, v.33, n.3, p.339347.

FAVERO, C.; JUCKSCH, I.; ALVARENGA, R. C.; COSTA, L. M. 2001. Modificações na população de plantas invasoras na presença de adubos verdes. Pesquisa Agropecuária Brasileira, Brasília, v. 36, n.11, p. 1355-1362.

FERREIRA, D. F. SISVAR: Um programa para análises e ensino de estatística. 
2008. Revista Symposium, Lavras, v. 6, n.2, p. 36-41.

FONTANÉTTI A.; CARVALHO G. J.; MORAIS A. R., ALMEIDA K.; DUARTE W. F. 2004. Adubação Verde no Controle de Plantas Invasoras nas Culturas de Alface-americana e de Repolho. Ciência e Agrotecnologia, Lavras, v. 28, n.5, p. 967-973.

GIOVANETTI, M.; MOSSE, B. 1980. An evaluction of techniques for measuring vesicular arbuscular mycorrhizal spores. New Phytologist, Oxford, v.84, n.3, p.489-500.

MACLEAN R. H.; LITSINGER J. A.; MOODY K.; WATSON A. K.; LIBETARIO E. M. 2003. Impact of Gliricidia sepium and Cassia spectabilis hedgerows on weeds and insect pests of upland rice. Agriculture, Ecosystems and Environment, Amsterdan, v.94, n.3, p.275-288.

MASCARENHAS, H. A. A; TANAKA, R. T.; COSTA, A. A.; ROSA, F. V.; COSTA, F. V. 1994. Efeito residual das leguminosas sobre o rendimento físico e econômico da cana-planta. Campinas: Instituto Agronômico, 15 p. (Boletim Científico, 32).

MATEUS G. P; CRUSCIOL C. A. C.; NEGRISO E. 2004. Palhada do sorgo de guiné gigante no estabelecimento de plantas daninhas em área de plantio direto. Pesquisa Agropecuária Brasileira, Brasília, v. 39, n. 6, p. 539542.

MONQUERO, P. A.; AMARAL, L. R.; INÁCIO, E. M.; BRUNHARA, J. P.; BINHA, D. P.; SILVA, P. V.; SILVA, A. C. 2009. Efeito de adubos verdes na supressão de espécies de plantas daninhas. Planta Daninha, Viçosa, MG, v. 27, n. 1, p. 85-95.

PANJA, B. N.; CHAUDHURI S. 2004. Exploitation of soil arbuscular mycorrhizal potential for AM-dependent mandarin orange plants by pre-cropping with mycotrophic crops. Applied Soil Ecology, Oxford, v. 26, n.2, p.249-255. PHILIPS, J. M.; HAYMAN, D. S. 1970. Improved procedures for cleaning roots and staining parasitic and vesicular arbuscular mycorrhizal fungi for rapid assessment of infection. Transactions of the British Mycological Society, London, v.55, n. 1, p.158-162.

PITELLI, R. A. 1985. Interferência das plantas daninhas em culturas agrícolas. Informe Agropecuário, Belo Horizonte, ano 11, n. 129, p. 16-27.

PUTNAM, A. R.; DEFRANK, J.; BARNES, J. P. 1983. Explotation of allelopathy for weed control in annual and perennial cropping systems. Journal of Chemical Ecology, Springer Link v.9, n.8, p.10011010.

PROCÓPIO, S.O.; SILVA, A.A.; VARGAS, L.; FERREIRA, F. A. 2003. Manejo de plantas daninhas na cultura da canade-açúcar. Viçosa: Suprema, 150 p.

QUAGGIO, J.A.; GODOY,I.J. Amendoim. In: RAIJ, B. VAN; CANTARELLA, H.; QUAGGIO, J.A.; FURLANI, A.M.C. 1996. Recomendações de adubação e calagem para o Estado de São Paulo. 2.ed. Campinas: IAC, p.192 (Boletim Técnico, 100)

SANTOS, C.A.B.; ZANDONÁ S.R.; ESPÍNDOLA J.A.A.; GUERRA J.G.M.; RIBEIRO R.L.D. 2011. Efeito de coberturas mortas vegetais sobre $\mathrm{O}$ desempenho da cenoura em cultivo orgânico. Revista Brasileira de Horticultura, Brasília, v.29, n.2, p. 103-107.

SEVERINO, F.J.; CHRISTOFFOLETI, P.J. 2001. Efeitos de Quantidades de Fitomassa de Adubos Verdes na Supressão de Plantas Daninhas. Planta Daninha, Viçosa-MG, v.19, n.2, p.223228.

TANIMOTO, T. 1964. The press method of cane analysis. Hawaiian Planter's Record, Hawaii v.57, n.2, p.133-150. 